\title{
Analysis of the properties of a steering shaft used as a back-up for a steer-by-wire system during system failure
}

\author{
K Hussain*, M Baharom, and A Day \\ School of Engineering Design and Technology, University of Bradford, Bradford, UK
}

The manuscript was received on 2 September 2008 and was accepted after revision for publication on 22 October 2008.

DOI: 10.1243/09544070JAUTO999

\begin{abstract}
An analysis is presented to determine the best selection criteria for the properties of a steering shaft to be used as a back-up apparatus for a steer-by-wire (SBW) system during system failure. The properties of interest are the steering-shaft stiffness and its damping coefficient. A mathematical model representing the failed state of an SBW system is derived, and a set of experiments to validate the model is presented. Once the model had been validated, further predictions of the car's handling behaviour for a range of steering-shaft properties and different road speeds were completed by simulations in MATLAB/Simulink. A minimum stiffness which did not cause the car to become unstable owing to overshoot was determined, and the minimum acceptable damping coefficient value was derived. It is concluded that the suggested stiffness and damping coefficient values increased the steering ratio, and the results of further investigations are presented, which confirm that the vehicle is safe to be driven in the event of SBW system failure if the recommended shaft properties are used.
\end{abstract}

Keywords: steer-by-wire system, failure, stiffness, damping, simulation, modelling, automotive, analysis

\section{INTRODUCTION}

The latest evolution in automotive steering technology is a steer-by-wire (SBW) system where an electrical system replaces the conventional mechanical connection through the steering shaft [1-3]. The absence of the need for a mechanical connection between the steering wheel and the road wheels means that SBW technology has many advantages in the automotive industry such as simplicity in design and packaging, safety during head-on collision, and the capability of performing active control $[\mathbf{4}, \mathbf{5}]$.

Although an SBW system has many advantages, the number of SBW systems currently fitted to cars in the marketplace is very small because of safety concerns in the event of system failure. If the moving vehicle can no longer be steered via the SBW, a back-up mechanical system is required for safety reasons. The

*Corresponding author: School of Engineering, Design and Technology, University of Bradford, Chesham Building, Richmond Road, Bradford, West Yorkshire, BD7 1DP, UK. email: k.hussain1@bradford.ac.uk concepts of back-up mechanical systems can be seen from the latest inventions in recent patent documents [3, 6-9]. These back-up systems may be activated using mechanical, electrical, or hydraulic devices.

The main objective of the research presented in this paper was to perform analysis and to determine the best steering-shaft properties to be selected for a mechanical back-up system which will ensure that a failed SBW vehicle is stable and safe to drive. The vehicle behaviour in the event of SBW system failure at various vehicle operating conditions has been analysed for a mechanical steering shaft of various stiffness and damping properties fitted to the vehicle. The vehicle behaviour is assessed by analysing the lateral accelerations and yaw velocities. Changes in the steering ratio, steering-wheel torque, and steering-wheel speed vary when the stiffness and the damping properties of the steering shaft have also been investigated.

The approach taken involved a mathematical model representing a steering system with a flexible shaft. An example of this type of system would be an electrical steering-wheel encoder with a power motor to actuate 
the steering-rack input pinion, plus a torque cable in an outer sheath which connects the steering wheel to the steering-rack input pinion. The resulting equations were solved using MATLAB/ Simulink, and the model was validated from experimental measurements. The vehicle behaviour at various stiffness and damping properties was then analysed.

\section{MATHEMATICAL MODELLING OF A STEERING SYSTEM}

A mathematical model of a failed SBW system was constructed on the basis of the free-body diagrams shown in Fig. 1. The free-body diagram consists of the steering-wheel assembly, a 'feel' motor and an actuator motor, both with gearing. All are attached to the vehicle front-wheel assembly. The input to the model is the steering-wheel angle as a function of time. The feel motor is used to provide torque feedback to the driver at the steering wheel, and the actuation motor provides the actuation force to the steered wheels.

Based on Figs 1(b) and (c), the dynamic equations describing the steering can be derived using Newton's second law of motion and can be presented as [10]

$$
\begin{aligned}
G & {\left[B_{\mathrm{l}}\left(\dot{\delta}_{\mathrm{sw}}-\dot{\delta}_{\mathrm{p}}\right)+K_{\mathrm{l}}\left(\delta_{\mathrm{sw}}-\delta_{\mathrm{p}}\right)\right] } \\
& -B_{\mathrm{Fw}} \dot{\delta}_{\mathrm{F}}-\tau_{\mathrm{f}}-M_{z \mathrm{~F}}=I_{\mathrm{Fw}}\left(\ddot{\delta}_{\mathrm{F}}+\dot{r}\right)
\end{aligned}
$$

where

$$
\tau_{\mathrm{f}}=F_{\mathrm{Cf}} \operatorname{sgn}\left(\dot{\delta}_{\mathrm{F}}\right)
$$

is the friction torque on the steering wheel, $F_{\mathrm{Cf}}$ is the frictional force,

$$
M_{z \mathrm{~F}} \approx C_{M \alpha_{\mathrm{F}}} \alpha_{\mathrm{F}}=C_{M \alpha_{\mathrm{F}}}\left(\delta_{\mathrm{F}}-\beta-\frac{a r}{V_{x}}\right)
$$

is the self-aligning moment,

$$
\delta_{\mathrm{p}}=G \delta_{\mathrm{F}}
$$

is the pinion rotation angle with $G$ the steering ratio and $\delta_{\mathrm{F}}$ the average front-steered-wheel angle, and $K_{\mathrm{l}}$ and $B_{1}$ are the stiffness and damping respectively of the steering shaft. The yaw rate is given by $r$ while the moment of inertia of the front-wheel assembly is given by $I_{\mathrm{Fw}}$. Definitions of all symbols can be found in the notation.

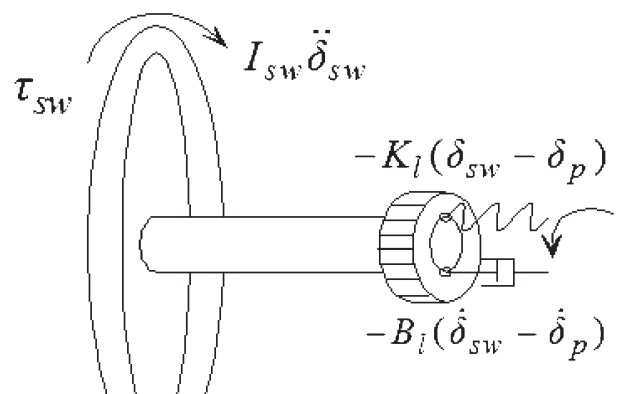

(a)

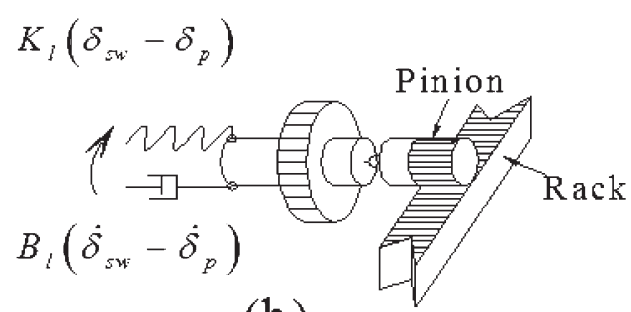

(b)

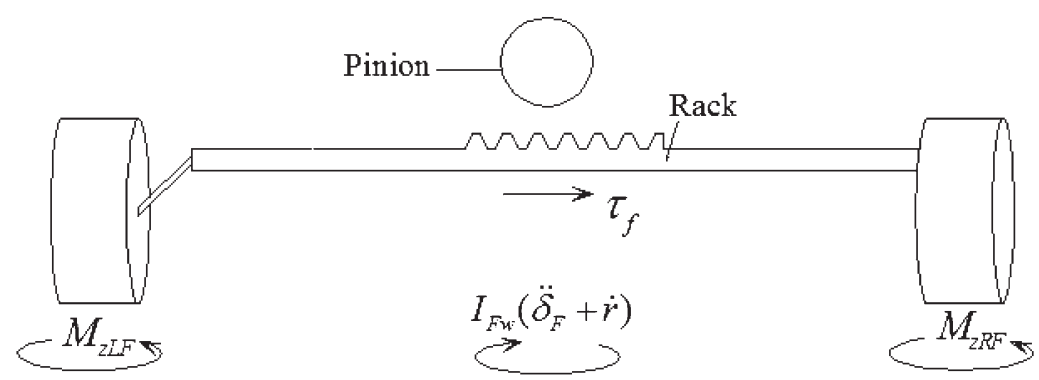

(c)

Fig. 1 Detailed free-body diagrams of SBW during system failure [10] 
Rearranging equation (1) gives

$$
\begin{aligned}
G\left(B_{\mathrm{l}} \dot{\delta}_{\mathrm{sw}}+K_{\mathrm{l}} \delta_{\mathrm{sw}}\right)= & I_{\mathrm{Fw}} \ddot{\delta}_{\mathrm{F}}+\left(B_{\mathrm{Fw}}+G^{2} B_{\mathrm{l}}\right) \dot{\delta}_{\mathrm{F}} \\
& +\left(C_{M \alpha_{\mathrm{F}}}+G^{2} K_{\mathrm{l}}\right) \delta_{\mathrm{F}}+F_{\mathrm{Cf}} \operatorname{sgn}\left(\dot{\delta}_{\mathrm{F}}\right) \\
& -C_{M \alpha_{\mathrm{F}}} \beta-\frac{a C_{M \alpha_{\mathrm{F}}}}{V_{x}}+I_{\mathrm{Fw}} \dot{r}
\end{aligned}
$$

A simplified vehicle dynamics model was used to test the steering dynamics [11]. The vehicle model simulates the sideslip angle $\beta$ and yaw velocity $r$. The resulting equation for the vehicle model is given below by equation (3). The input to the model is the calculated steering-wheel angle $\delta_{\text {sw. }}$.

Equation (2) can be simplified in order to obtain a relationship between the feel motor positional angles and the front-steered-wheel angles where the formula consists of $\beta, r$, and $\delta_{\mathrm{F}}$. The Coulomb friction term $F_{\mathrm{Cf}}$ was assumed to be negligible; a detailed study of this force in a steering system has been given by Post and Law [12]. Therefore, the final expression for equation (2) could be simplified as

$$
\begin{aligned}
G\left(B_{\mathrm{l}} \delta_{\mathrm{sw}}+K_{\mathrm{l}} \delta_{\mathrm{sw}}\right)= & Q_{\ddot{\delta}_{\mathrm{F}}} \ddot{\delta}_{\mathrm{F}}+Q_{\dot{\delta}_{\mathrm{F}}} \dot{\delta}_{\mathrm{F}}+Q_{\delta_{\mathrm{F}}} \delta_{\mathrm{F}}+Q_{\beta} \beta \\
& +Q_{r} r+F_{\mathrm{Cf}} \operatorname{sgn}\left(\dot{\delta}_{\mathrm{F}}\right)
\end{aligned}
$$

where

$$
\begin{aligned}
& Q_{\ddot{\delta}_{\mathrm{F}}}=I_{\mathrm{FW}} \\
& Q_{\dot{\delta}_{\mathrm{F}}}=B_{\mathrm{FW}}+G^{2} B_{\mathrm{l}} \\
& Q_{\delta_{\mathrm{F}}}=C_{M \alpha_{\mathrm{F}}}+G^{2} K_{\mathrm{l}}+\frac{a I_{\mathrm{FW}} C_{F \alpha_{\mathrm{F}}}}{I_{z z}} \\
& Q_{\beta}=\frac{I_{\mathrm{FW}}}{I_{z z}}\left(b C_{F \alpha_{\mathrm{R}}}-a C_{F \alpha_{\mathrm{F}}}\right)-C_{M \alpha_{\mathrm{F}}}
\end{aligned}
$$

$$
Q_{r}=-\frac{a C_{M \alpha_{\mathrm{F}}}}{V_{x}}-\frac{I_{\mathrm{Fw}}}{I_{z z} V_{x}}\left(a^{2} C_{F \alpha_{\mathrm{F}}}+b^{2} C_{F \alpha_{\mathrm{R}}}\right)
$$

Using equation (3), a transfer function for the dynamic system was derived [13]. The input to the complete system is the steering-wheel angle $\delta_{\mathrm{sw}}$ and the output is the front-steered-wheel angle $\delta_{\mathrm{F}}$. The corresponding output $\delta_{\mathrm{F}}$ is used as the input to the vehicle dynamics model. The outputs from the vehicle model, namely the yaw and the sideslip angles, are then used as the external inputs to the transfer function, multiplying their specific coefficients and the transfer functions accordingly. A description of the computational processes is shown in Fig. 2. The output parameters of the model are the yaw velocity $r$, the lateral acceleration defined by $a_{y}=\dot{\beta} V_{x}+r V_{x}$, and the frontsteered-wheel angle $\delta_{\mathrm{F}}$.

The torque applied at the steering wheel by the driver can be represented by

$$
\begin{aligned}
& \tau_{\mathrm{sw}}-K_{\mathrm{l}}\left(\delta_{\mathrm{sw}}-G \delta_{\mathrm{F}}\right)-B_{\mathrm{l}}\left(\dot{\delta}_{\mathrm{sw}}-G \dot{\delta}_{\mathrm{F}}\right)=I_{\mathrm{sw}} \ddot{\delta}_{\mathrm{sw}} \\
& \Rightarrow \tau_{\mathrm{sw}}=\left(I_{\mathrm{sw}} \ddot{\delta}_{\mathrm{sw}}+B_{\mathrm{l}} \dot{\delta}_{\mathrm{sw}}+K_{\mathrm{l}} \delta_{\mathrm{sw}}\right) \\
&-\left(G B_{\mathrm{l}} \dot{\delta}_{\mathrm{F}}+G K_{\mathrm{l}} \delta_{\mathrm{F}}\right)
\end{aligned}
$$

As the amount of torque applied to the steering wheel varies, a mathematical formula to predict the relationship between the torque and the steering wheel velocity was derived (see equation (4)). In this case, the characteristic of the torque applied at the steering wheel is the input and the corresponding output is the steering wheel velocity. Equations (3) and (4) can be combined and the resulting formula is represented in the Simulink block diagram shown in Fig. 3. This can be added to the block diagram of Fig. 2.

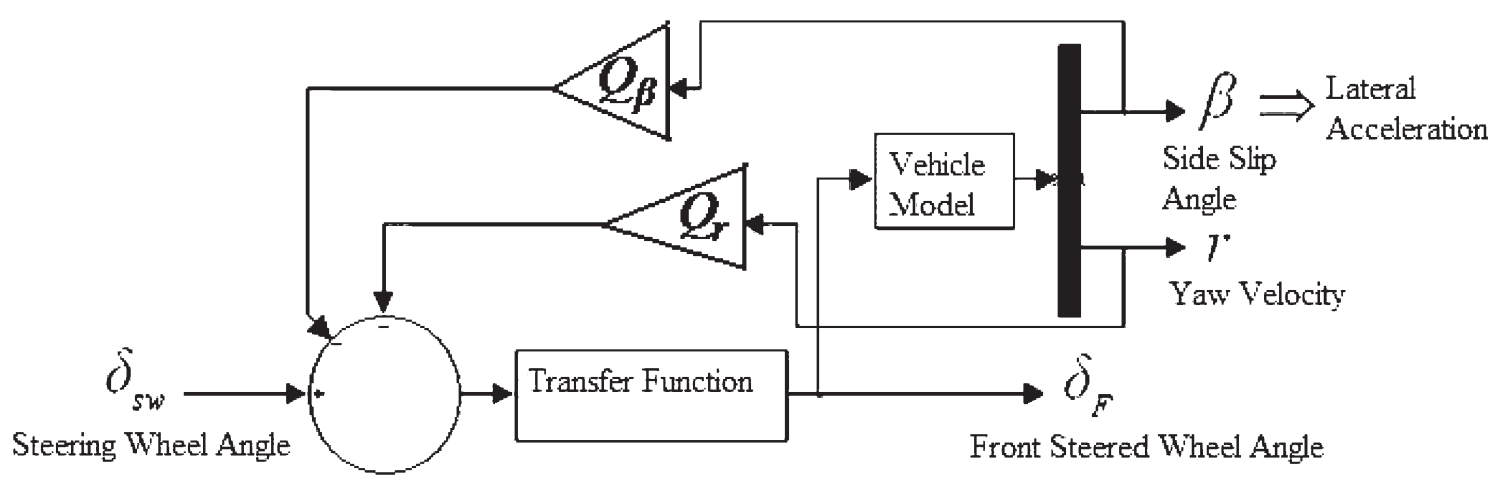

Fig. 2 Block diagrams of the Simulink program for SBW during system failure 


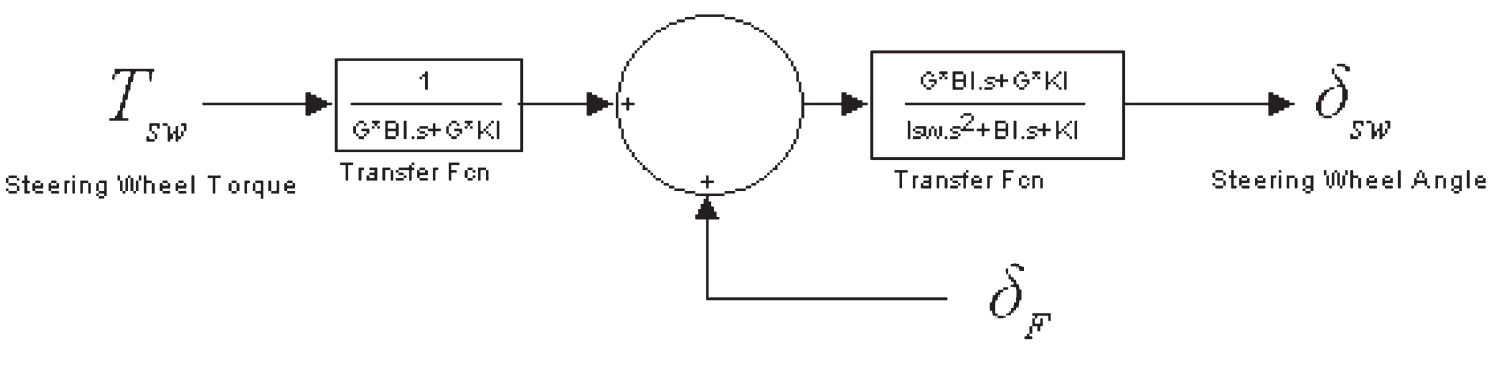

Front Steered 'ultheel Angle

Fig. 3 Block diagram of a Simulink program that uses the steering-wheel torque as input

\section{EXPERIMENTAL WORK}

Experimental work was carried out to validate the simulation model and to test the vehicle-handling performance when fitted with a steering shaft of variable stiffness and damping properties.

The experiments were conducted on a small car of mass approximately $1200 \mathrm{~kg}$ including the front-seat passenger and driver. Three flexible intermediate steering shafts with stiffnesses of $5 \mathrm{~N} \mathrm{~m} / \mathrm{rad}, 10 \mathrm{~N} \mathrm{~m} /$ $\mathrm{rad}$, and $15 \mathrm{Nm} / \mathrm{rad}$ were fabricated to replace the original intermediate steering shaft of the vehicle. The vehicle had an hydraulic power-assisted steering system which was deactivated by draining the hydraulic fluid from the vehicle in order to minimize any effect of fluid damping. A DL1 [14] data logger was used to log the data; it had a high-accuracy Global Positioning System (GPS) and an accelerometer built in. The data logged included the time, vehicle acceleration, vehicle speed, distance, GPS position, power output, yaw velocity, and cornering radius. The sampling time interval for all the experiments was set at $0.01 \mathrm{~s}$. The steering-wheel angle was measured by a 10 turn potentiometer, and the signal was recorded by the data logger.

The experiments were conducted on a two-way single-lane test track. A series of extreme single lanechange manoeuvres was conducted; the test car was accelerated from rest to a specified constant speed before the manoeuvre was initiated. The three steering shafts were fitted and tested in turn on the car. For safety reasons, the vehicle speed for each was limited to a maximum of $20 \mathrm{~km} / \mathrm{h}$. Each experiment was repeated three times. The actual speed of each test was recorded.

\section{RESULTS AND DISCUSSION}

\subsection{Validation of the mathematical model}

The raw experimental data recorded by the data logger were processed and then filtered in order to eliminate noise. The data used for the validation of the mathematical model were the yaw velocity and lateral acceleration as functions of time. The theoretical results were analysed using the derived mathematical formula and the Simulink program (Fig. 2). The measured steering-wheel angle data were input to the numerical model together with the average values of the vehicle speed.

The experimental results and the computational results are compared and presented here in terms of the output response for yaw velocity and lateral acceleration (Figs 4(c) and (d), 5(c) and (d), and 6(c) and (d)). The characteristic plots of the steeringwheel angle and actual vehicle speed as functions of time are shown in Figs 4(a) and (b), 5(a) and (b), and 6(a) and (b). In general, the predicted results agreed with the measured data.

It was concluded that the derived mathematical formula was correct and valid for the prediction of suitable steering-shaft properties for an SBW backup system.

\subsection{Predictions using the steering-wheel angle as input}

Two input characteristics were chosen, namely the sinusoidal and step inputs as shown in Figs 7(a) and (b) respectively. These two conditions were chosen because they represented the worst case that might happen during SBW failure. The road conditions were assumed to be smooth and level.

Four analyses were performed using each steering-wheel input characteristic. The first analysis was to determine the vehicle behaviour when the steering-shaft stiffness was varied from $2 \mathrm{Nm} / \mathrm{rad}$ until the vehicle behaviour approached that of the manual steering system, while its damping value was maintained at $2 \mathrm{Nms} / \mathrm{rad}$. The vehicle speed was set at $48 \mathrm{~km} / \mathrm{h}$.

The second analysis studied the effect of increasing the steering-shaft damping coefficient while keeping the stiffness $K$ at a specified value of $5 \mathrm{~N} \mathrm{~m} / \mathrm{rad}$. 


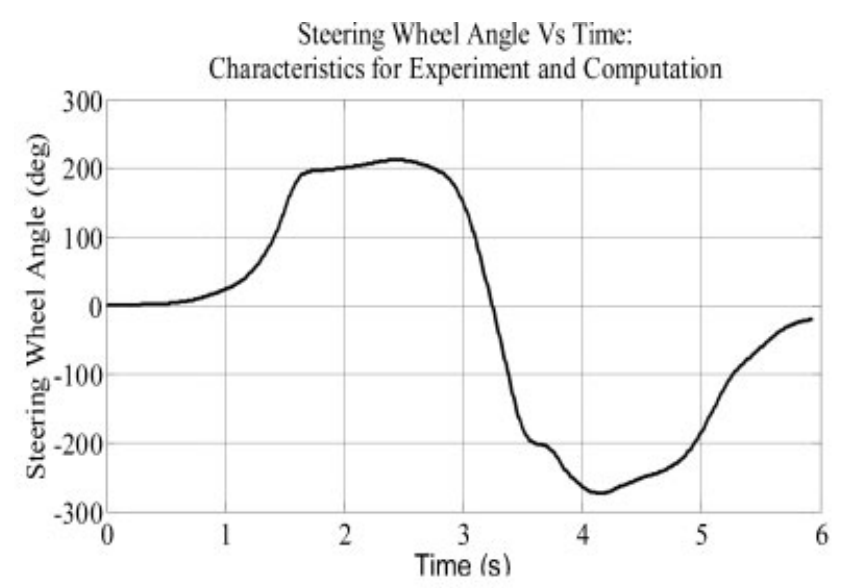

(a)

Yaw Velocity Vs Time:

Average Speed, $\mathrm{Vx}=11.75 \mathrm{mph}$, Average Stiffness, $\mathrm{K}=5 \mathrm{Nm} / \mathrm{rad}$

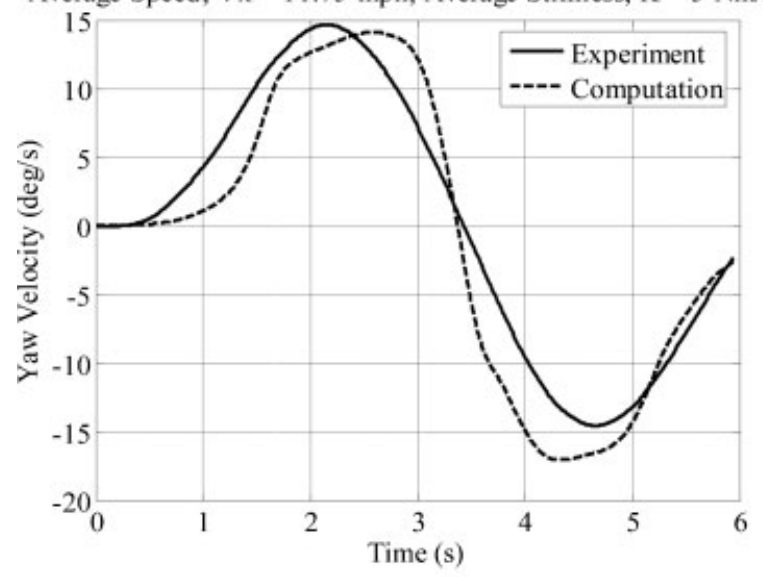

(c)

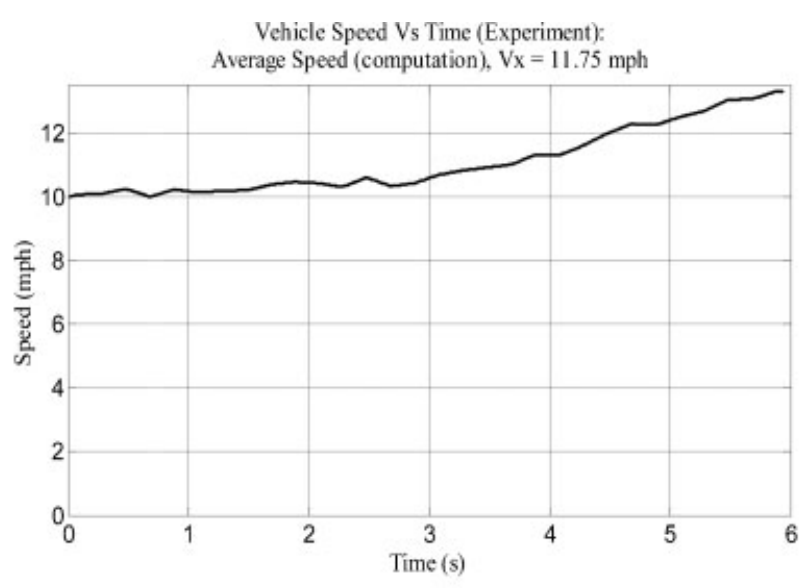

(b)

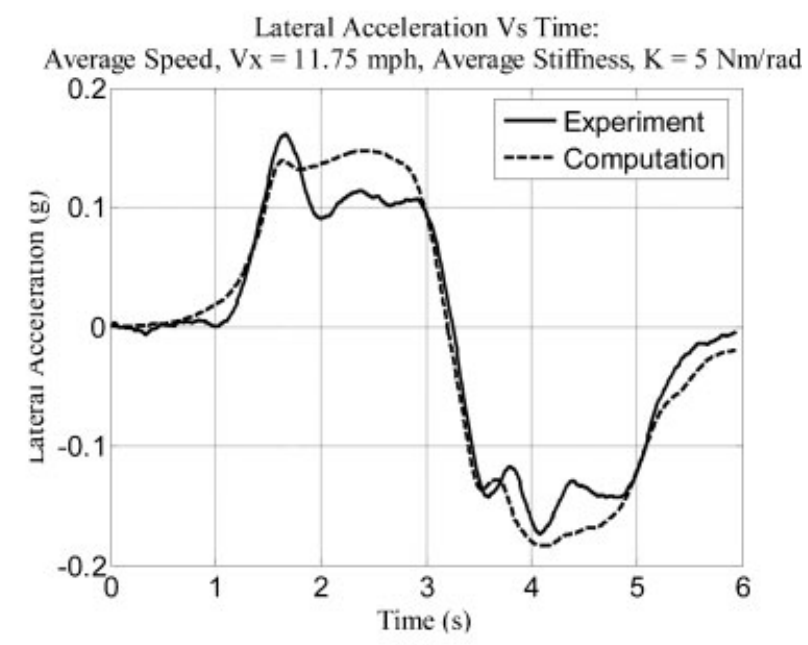

(d)

Fig. 4 Output results for an average stiffness $K=5 \mathrm{Nm} / \mathrm{rad}$

The vehicle speed was again $48 \mathrm{~km} / \mathrm{h}$. A stiffness value of $5 \mathrm{~N} \mathrm{~m} / \mathrm{rad}$ was used in the analysis because this was shown to be sufficient for the stability and safety of the car used. An upper limit of damping coefficient was estimated.

The third analysis was made to predict the car's steering behaviour when the road speed was increased for the lowest value of the steering-shaft stiffness and damping coefficient $K=5 \mathrm{~N} \mathrm{~m} / \mathrm{rad}$ and $B=2 \mathrm{~N} \mathrm{~m} \mathrm{~s} / \mathrm{rad}$.

The fourth analysis was to determine the effect of increased road speed on the car steering behaviour with a failed SBW system fitted with the lowest back-up steering-shaft stiffness, $5 \mathrm{~N} \mathrm{~m} / \mathrm{rad}$, and a high damping value of $200 \mathrm{Nms} / \mathrm{rad}$. For both the third and the fourth analyses, the minimum road speed was set as $16 \mathrm{~km} / \mathrm{h}$ while the maximum speed was $80 \mathrm{~km} / \mathrm{h}$.

The predicted results for all the analyses were the yaw velocities, which were plotted against time for the two inputs of the steering-wheel angle characteristics. The yaw velocities were the only outputs selected for analysis because the trends seen in the lateral accelerations and front-steered-wheel angles were similar to those seen in the yaw velocities.

\subsection{Results and discussions for the steering- wheel angle inputs}

The output results for the first analysis are shown in Fig. 8, and those from the second analysis are illustrated in Fig. 9. The results from the third analysis are shown in Fig. 10 and those from the last analysis are shown in Fig. 11.

Figures 8(a) and (b) show the yaw responses for sinusoidal and ramp inputs respectively to the steering wheel. It can be observed that, the higher the stiffness of the steering shaft, the higher are the peaks of the maximum yaw velocities. The incre- 


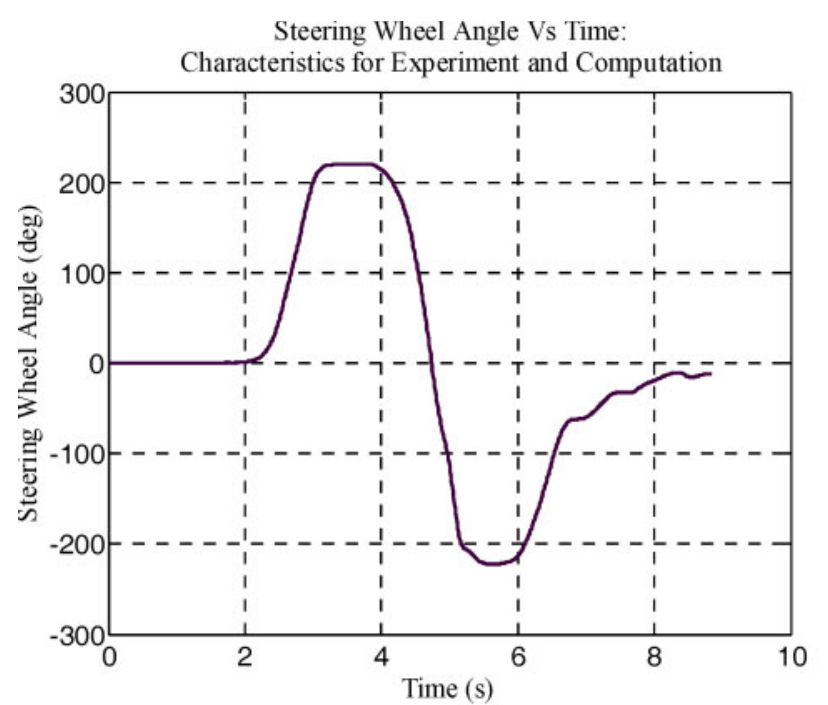

(a)

Yaw Velocity Vs Time:

Average Speed, $\mathrm{Vx}=8.5 \mathrm{mph}$, Average Stiffness, $\mathrm{K}=15 \mathrm{Nm} / \mathrm{rad}$

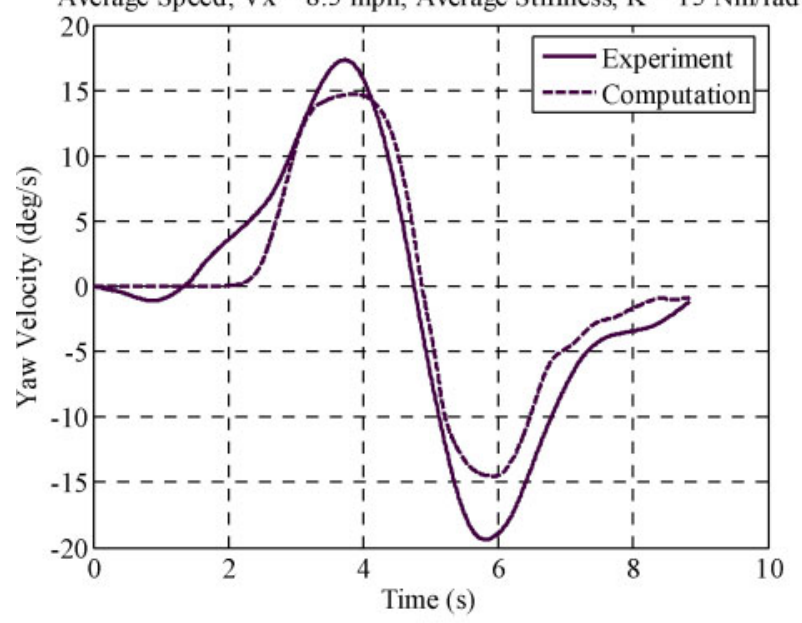

(c)

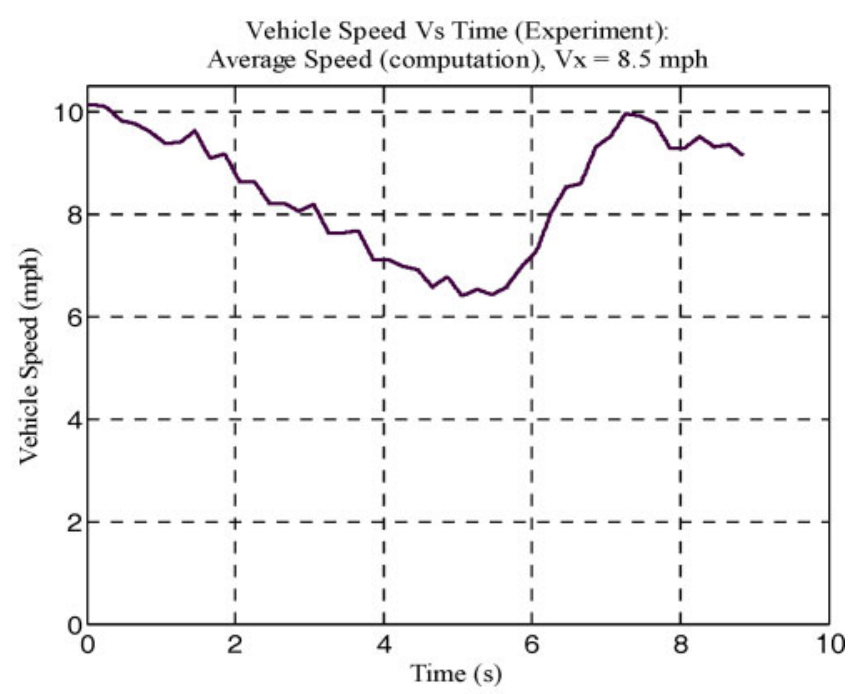

(b)

Lateral Acceleration Vs Time:

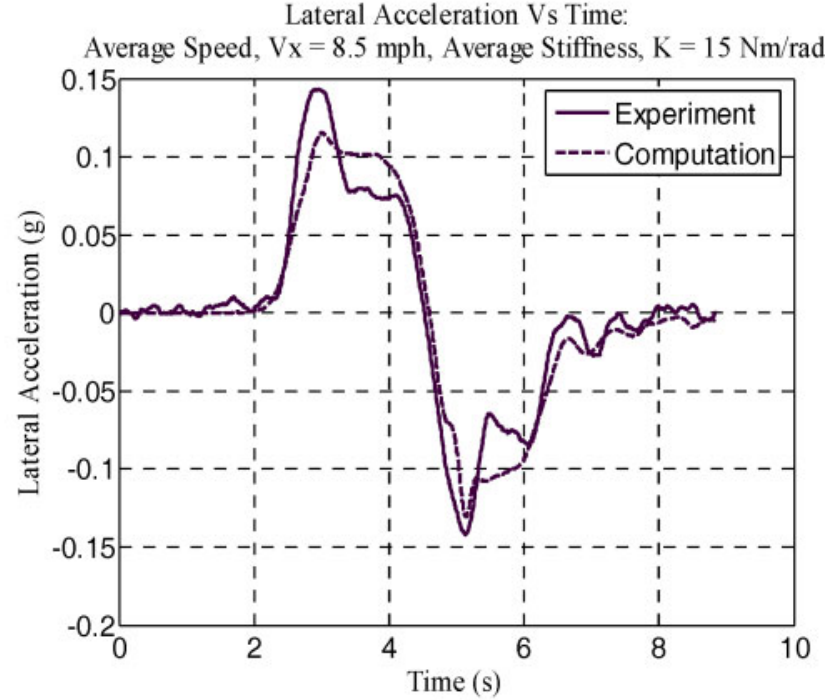

(d)

Fig. 5 Output results for an average stiffness $K=10 \mathrm{~N} \mathrm{~m} / \mathrm{rad}$

mental rate of the peak values, however, decreases as the stiffness value increases. As the stiffness of the steering shaft increases to rigid, the peak values approach the results expected from a conventional mechanical steering system. It was also observed that the steering ratio decreases with increase in the shaft stiffness, and the incremental rate of the steering ratio increases as the stiffness value decreases.

For the sinusoidal input (Fig. 8(a)), the highstiffness shaft yields a yaw velocity response which is very close to the conventional shaft. As the shaft stiffness is decreased, the yaw velocity response becomes increasingly different (smaller amplitude) although the shape is retained. The curves in between them are not symmetric and have offsets with some time lag. The reason for the non- symmetry and offset could be due to the contribution of damping forces. The elasticity of the steeringshaft stiffness means that it takes a longer time for sufficient steering torque to develop. Once a sufficient angle of twist is reached, the speed of the front-steered-wheel angle increases; therefore the contribution from damping forces becomes higher. At high stiffnesses, the contribution of damping forces is small relative to other forces while, at low stiffnesses, the forces due to stiffness and damping are almost similar.

For a step input (Fig. 8(b)), overshoot is observed when the curves approach either low stiffness values or high stiffness values. Overshoot for the case of low stiffness is undesirable because more angular displacement of the steering wheel (and hence driver 
Steering Wheel Angle Vs Time:

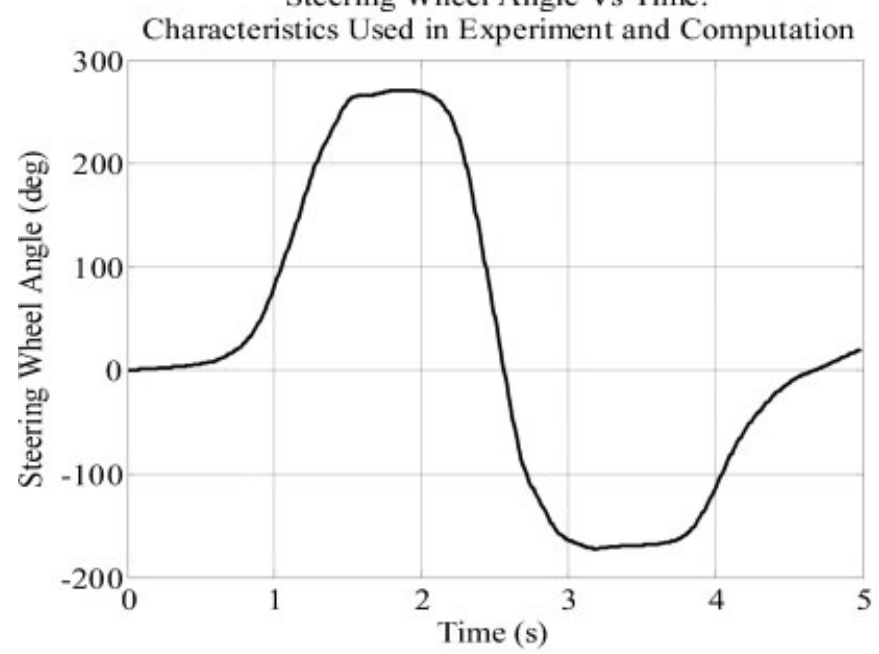

(a)

Yaw Velocity Vs Time:

Average Velocity, $\mathrm{Vx}=11.75 \mathrm{mph}$, Average Stiffness, $\mathrm{K}=10 \mathrm{Nm} / \mathrm{rad}$

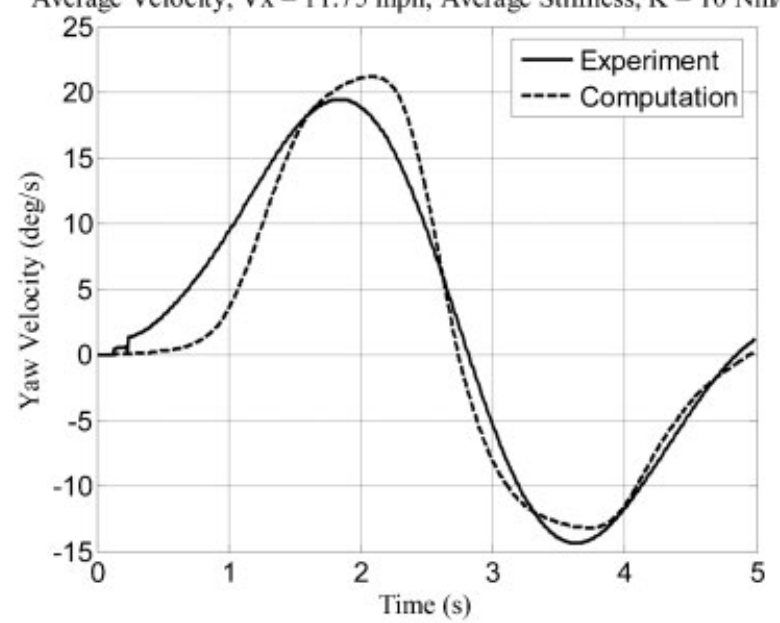

(c)
Vehicle Speed Vs Time (Experiment): Average Speed (computation), $\mathrm{Vx}=11.75 \mathrm{mph}$

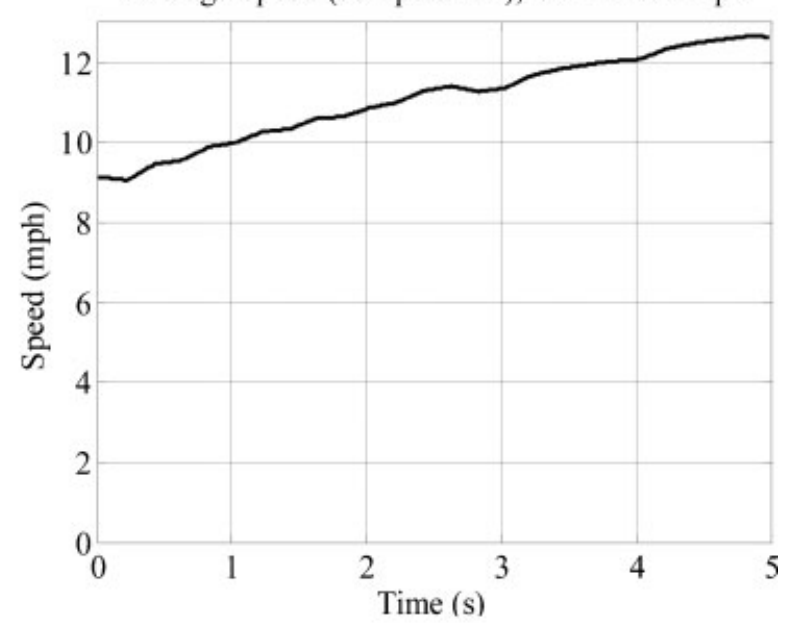

(b)

Lateral Acceleration Vs Time:

Average Velocity, $\mathrm{Vx}=11.75 \mathrm{mph}$, Average Stiffness, $\mathrm{K}=10 \mathrm{Nm} / \mathrm{rad}$

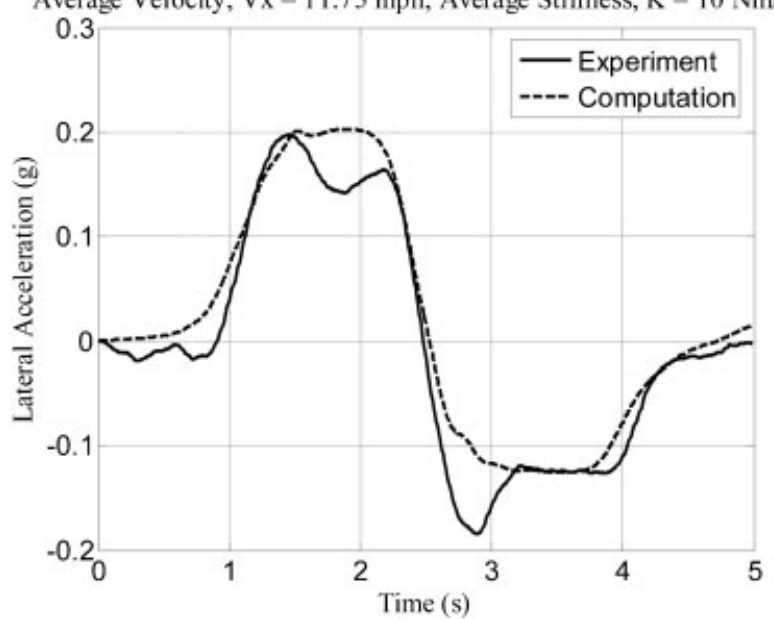

(d)

Fig. 6 Output results for an average stiffness $K=15 \mathrm{Nm} / \mathrm{rad}$

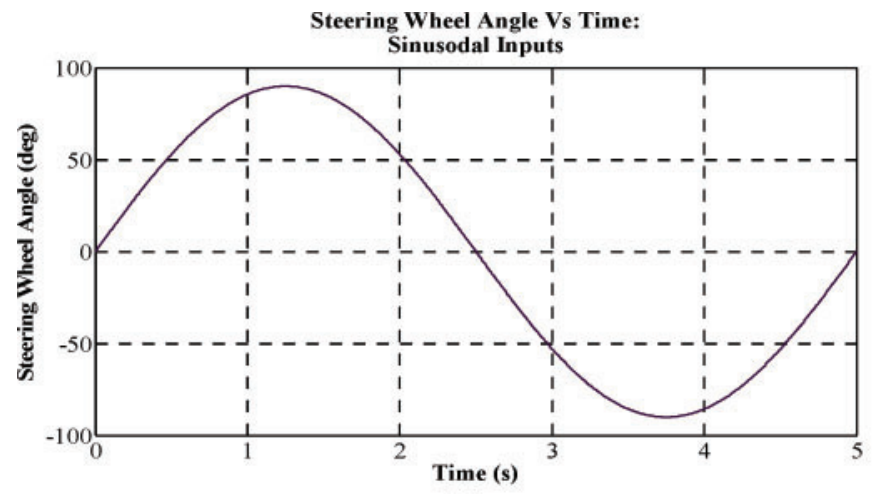

(a)

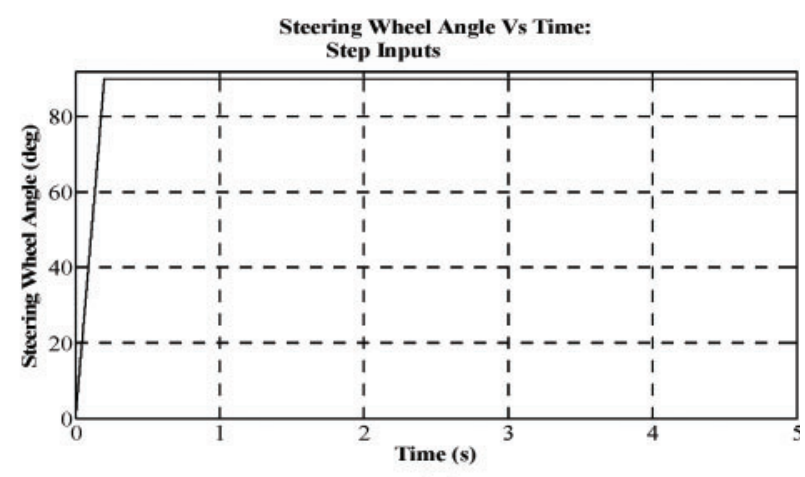

(b)

Fig. 7 Steering-wheel angle characteristics used in all analyses 


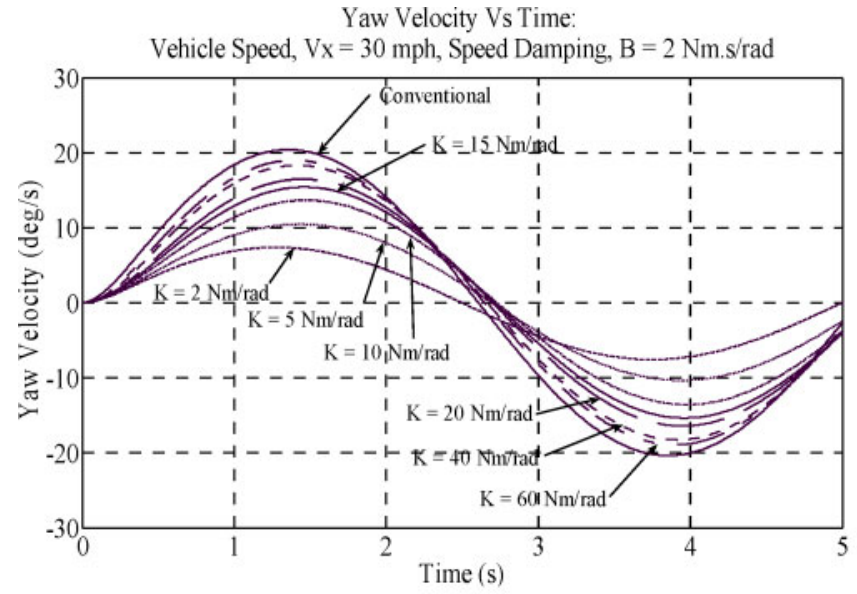

(a)

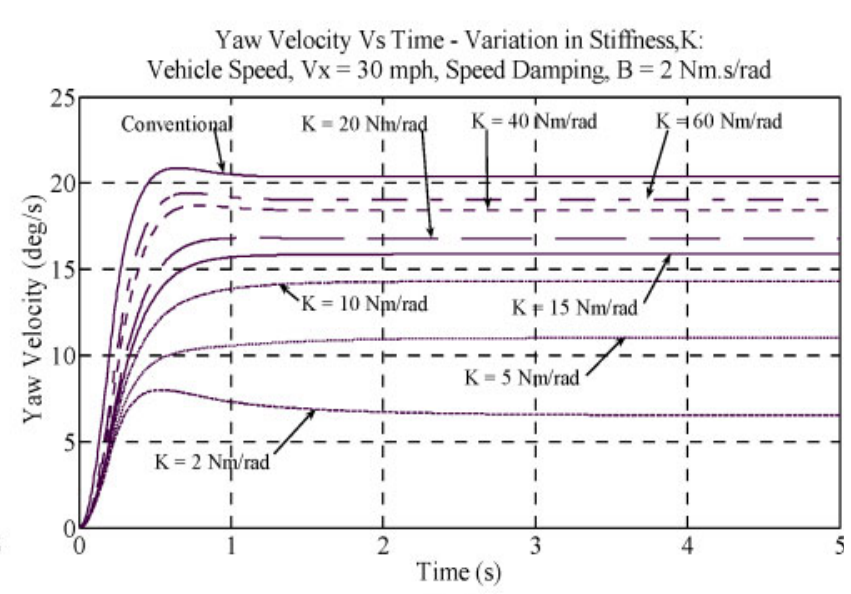

(b)

Fig. 8 Variation in stiffness at a specified speed and speed damping value

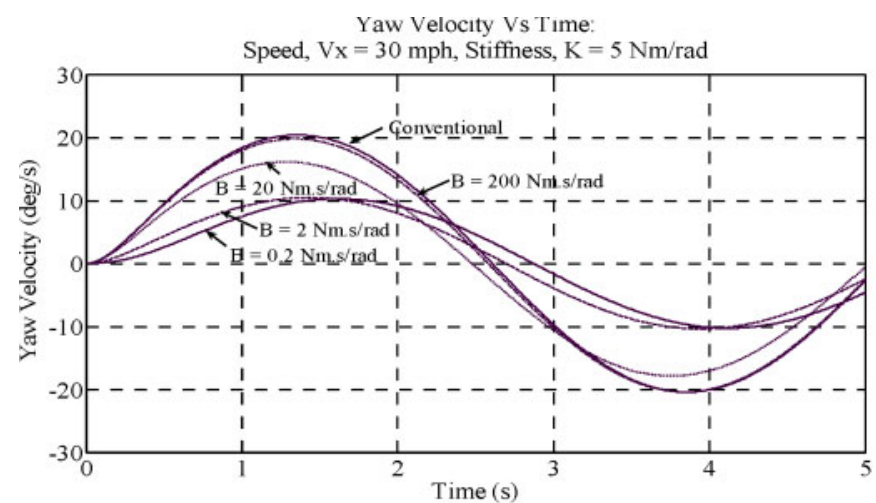

(a)

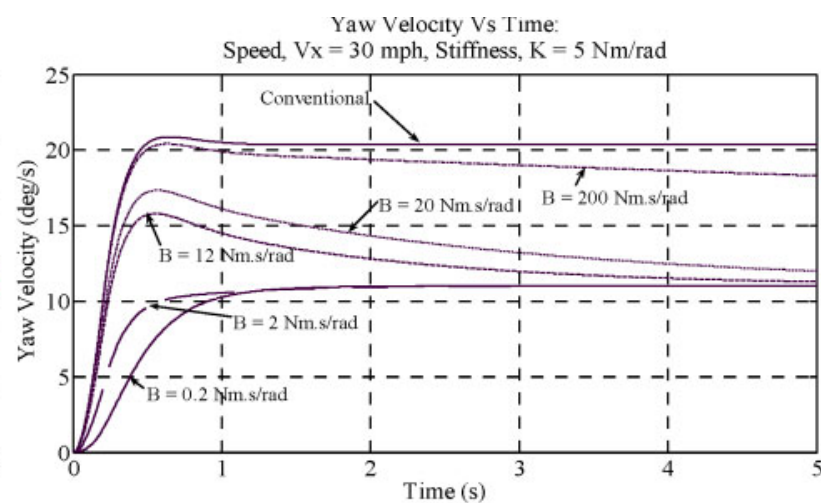

(b)

Fig. 9 Variation in the damping values at a specified speed and stiffness

anticipation) is required to turn and control the car through the steering wheel. The increase in the required angle of twist will result in a delay in the response time. Because of the delay in the response time, more energy is being stored and the restoring

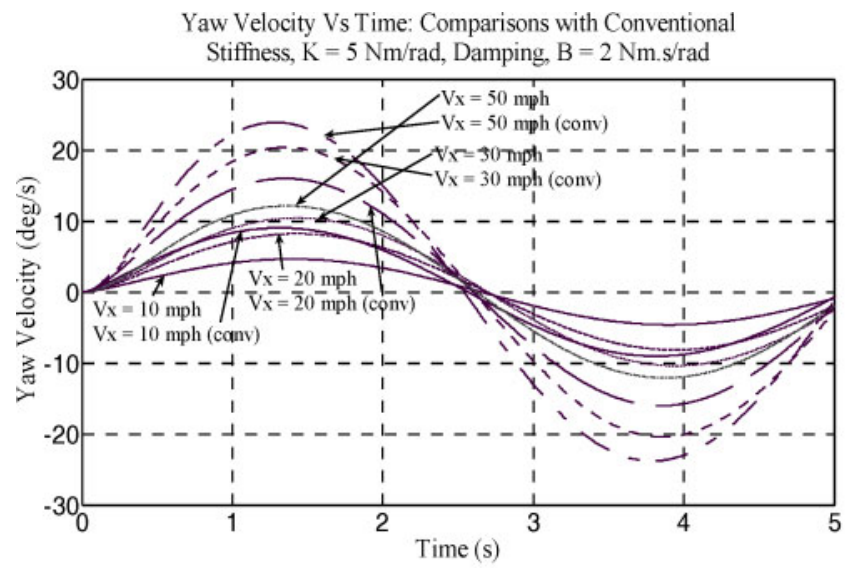

(a) of energy will increase the inertia of the system, this hence leads to overshoot. The percentage of overshoot is also greater for the case of low stiffness which causes ride discomfort and also takes a longer time to settle.

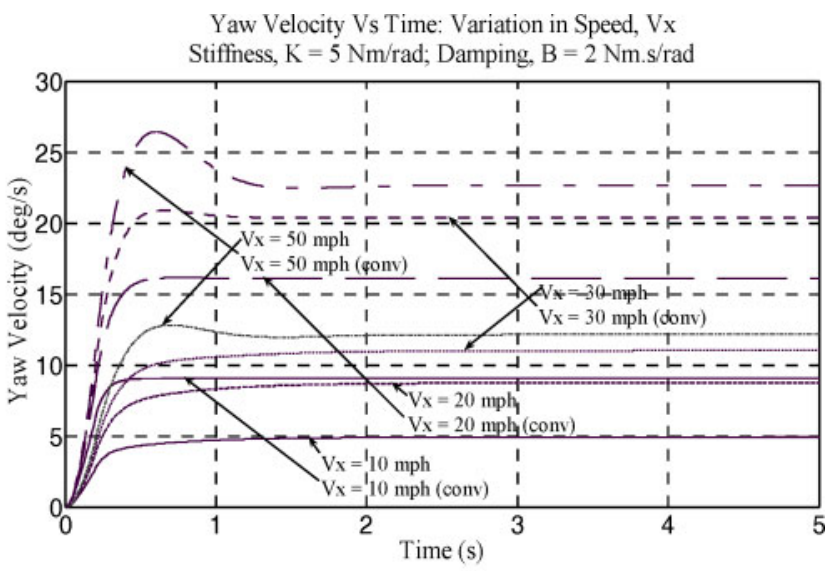

(b)

Fig. 10 Variation in the vehicle speed at a specified stiffness and a low-speed damping value 


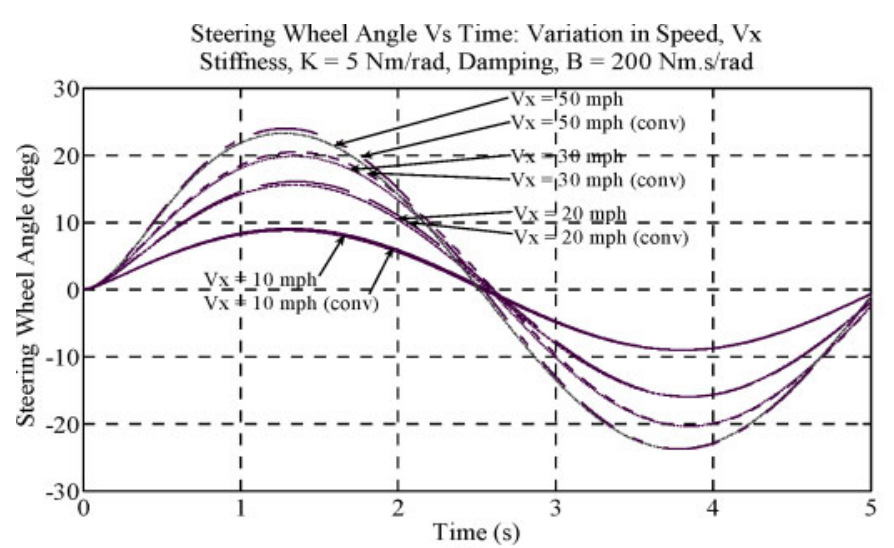

(a)

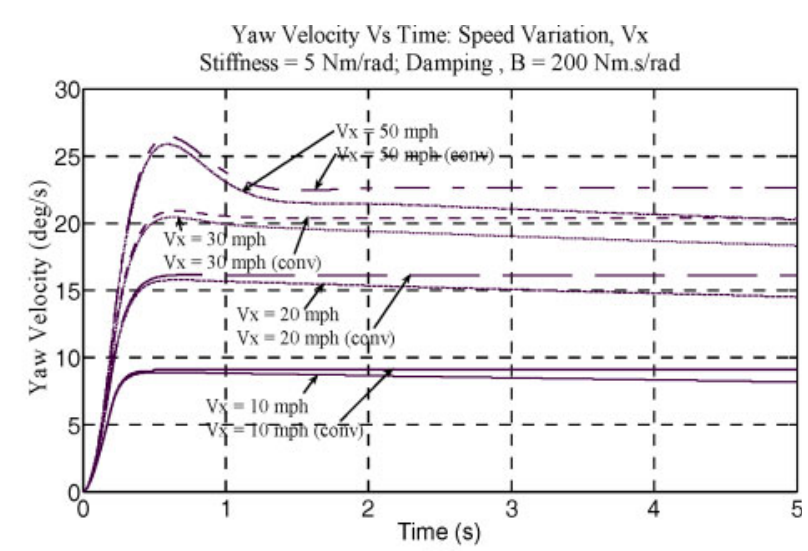

(b)

Fig. 11 Variation in the vehicle speed at a specified stiffness and a high-speed damping value

It can be observed from Figs 9(a) and (b) that, when the stiffness value is fixed and the damping coefficient is varied, higher damping in the steering shaft generates a yaw velocity that is closer to that of a conventional mechanical steering system.

For the sinusoidal input (Fig. 9(a)), it can be found that the incremental rate of the peak values decreases as the damping value increases. Owing to the very low stiffness of the steering shaft, the damping forces dominate the other forces. However, at low damping, the contribution of steering-shaft stiffness is significant.

It can be observed from Fig. 9(b) that, as the damping decreases, the yaw velocity decreases, approaching the steady state value of the steering shaft with the lowest damping. The explanation of this is based on the different characteristics of the steering-wheel inputs. For the sinusoidal case, although the steering-wheel velocity varies throughout the cycle, the process is continuous. On the other hand, for the step input, the steering-wheel velocity is initially constant but suddenly drops to zero. The presence of the steering-wheel velocity contributes to the amount of damping force applied to the system. As the velocity becomes zero, there is no longer any damping force to assist the motion. If the damping values are within the range of minimum acceptable and maximum achievable, the vehicle may be unstable during the step-steer condition as shown in Fig. 8(b) owing to overshoot.

The other finding was that overshoot was found to be minimal at low steering-shaft damping. Damping values of $0.2 \mathrm{~N} \mathrm{~m} \mathrm{~s} / \mathrm{rad}$ and $2 \mathrm{~N} \mathrm{~m} \mathrm{~s} / \mathrm{rad}$ did not result in overshoot but the latter is preferable because the response time is faster. This is because, as the damping values are small, the force contributed by the damping becomes negligible with respect to the stiffness forces.
It can be concluded that, although the SBW back-up steering-shaft stiffness may be significantly lower than that of a conventional mechanical steering system, manageable car-handling control can be achieved by combining it with high damping, but only for continuous steering-wheel movement. For the case of step-steer, high angular acceleration of the steering wheel emphasizes the overshoot characteristic of the car under failed SBW conditions; therefore, in order to maintain manageable carhandling control when performing a step-steer manoeuvre, the driver must always apply torque on the steering wheel smoothly and continuously. Although this can be done, it may not be very practical as the driver's steering input must depend on the requirements of the particular route, and the car's handling performance, and not on steering system needs. However, it would be expected that active steering intervention may solve this dilemma.

It can be seen from Figs 10(a) and (b) that for both a conventional mechanical steering system and a flexible steering shaft as analysed here for a failed SBW condition, as vehicle speeds increase, the yaw velocities also increase. For the sinusoidal input case (Fig. 10(a)), the ratio (approximately 2) of the peak values of the yaw velocities for the two cases are maintained and not affected by a change in the road speed.

For the step input case (Fig. 10(b)), the ratio of the settling values of the yaw velocity for the two cases are also maintained and not affected by a change in the road speed. However, overshoot increased as road speed increased.

It can be concluded from Figs 11(a) and (b) that, with a high steering-shaft damping coefficient, the car's handling behaviour during SBW failure can be comparable with that of a conventional mechanical steering system. Although the reduction in the yaw velocity increases as the road speed increases for the 
case of step input, the effect is small and may not affect the smoothness of driving as the driver can apply continuous movement to the steering wheel.

Based on the analysis performed in this section, several conclusions can be drawn about the selection of the best properties of a back-up steering shaft for an SBW system. There is a minimum acceptable stiffness value which causes the car to be stable without overshoot during SBW system failure, and this was found to be the best of all. The flexibility of the steering shaft provides a packaging advantage, since a cable could be used for the back-up shaft and the car could be more stable with minimal overshoot. The characteristics of the yaw response are similar to that of a car fitted with conventional mechanical steering.

As for the case of the damping coefficient, it has been demonstrated that the best choice is either to have a minimum (zero) damping or to have high damping of about $200 \mathrm{~N} \mathrm{~m} \mathrm{s/rad}$. Since zero damping is impossible, a high damping would be preferred, for which the car's handling performance will be similar to that of a conventional mechanical steering system. However, although having a high damping may be an advantage, the design of a high-damping system may sacrifice the packaging benefit, and a decision will rely on the design of suitable dampers.

The other option is to select a minimum acceptable damping value. A separate damper would not be required since residual damping would be present naturally in the system, being functions of the materials and design of the system, e.g. a cable.

Although having a low stiffness and low damping is preferable, the steering ratios are seen to increase and this would require a faster response time to control the steering wheel. For example, based on the previous analysis, the most preferable steering-shaft stiffness is $5 \mathrm{Nm} / \mathrm{rad}$ but this value has doubled the system's steering ratios. When the steering ratio increases, the driver needs to turn the steering-wheel angle twice as much with a faster speed. It is questionable whether the driver will manage to handle the situation and this is discussed later.

\subsection{Results and discussion for the steering-wheel torque inputs}

Predictions using the steering-wheel torque as input to the mathematical model allow the relationship with the steering-wheel velocity to be understood. These predictions are required because the experiments could not provide sufficient information. The formula and procedure for modelling the steeringwheel torque as input were discussed previously in section 2 (equation (4)). For all analyses, the torque applied at the steering wheel has been assumed to be constant $(10 \mathrm{Nm})$ as shown in Fig. 12(a). The output results are the steering-wheel velocity, angular velocity, and lateral acceleration as functions of time, which are shown in Fig. 12.

From Fig. 12(b), different characteristics of steering-wheel velocities can be observed for different steering-shaft stiffnesses when subjected to an equal amount of steering torque. The lower the stiffness value of the steering shaft, the higher is the steeringwheel velocity during the initial period. After a certain time period, all the plots indicate the approach to the same trend of velocity behaviour. Because of the different stiffness values, different angles of twist are required for each case in order to achieve the final state condition and each will also require a different time. The final velocity state is when the steeringwheel acceleration becomes constant. Therefore, in this case it should be a straight-line curve with a slope representing the acceleration value.

This analysis suggests that applying the amount of torque required for a certain manoeuvre during emergency is more important than applying the required steering-wheel velocity. This is because, when a certain amount of torque is applied at the steering wheel, the resulting steering-wheel velocity will vary automatically depending on the steeringshaft stiffness.

\section{SUMMARY AND CONCLUSIONS}

All the mathematical models derived here have been validated with experimental data. The mathematical models have been used to predict the car-handling response during SBW system failure with simulated different properties of a back-up steering shaft, i.e. the stiffness and damping. It was found that the best stiffness value is the minimum acceptable stiffness value that does not cause the car to be unstable owing to overshoot. Low stiffness is desirable because of the packaging advantage, and it causes the vehicle to be more stable and to produce outputs with characteristics similar to the conventional system. The characteristics of vehicle performance were not affected by the road speed.

The best choice of damping value is either a minimum acceptable value or the highest possible value. The highest possible value may lead to disadvantages in terms of design and packaging benefits. The minimum acceptable damping value may be found naturally in the steering shaft without any need for separate dampers, because the damp- 


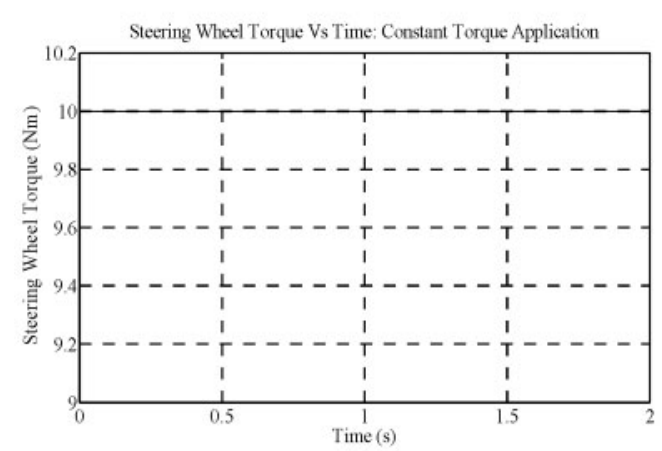

(a)

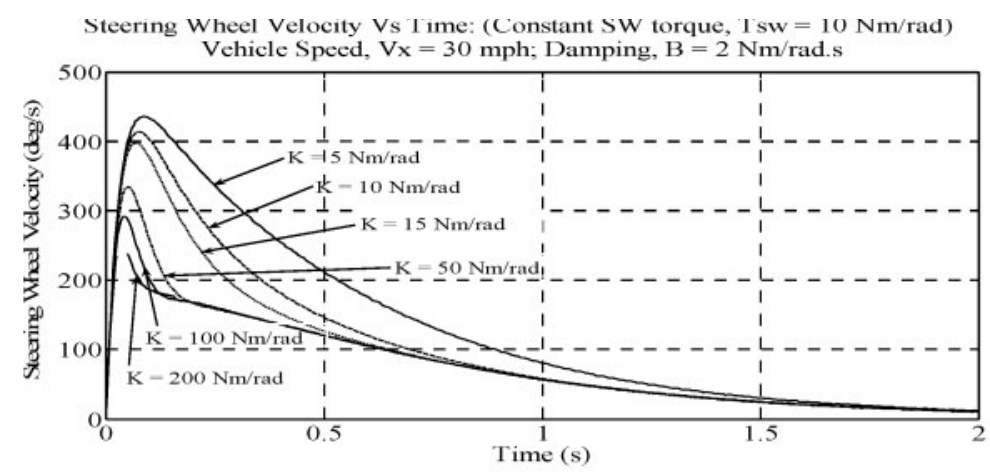

(b)

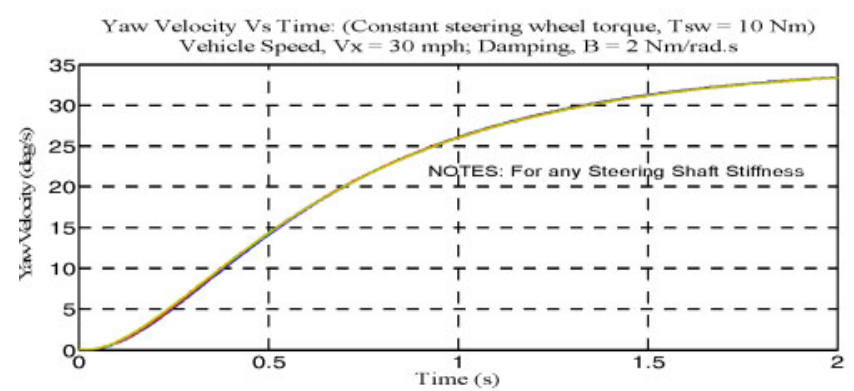

(c)

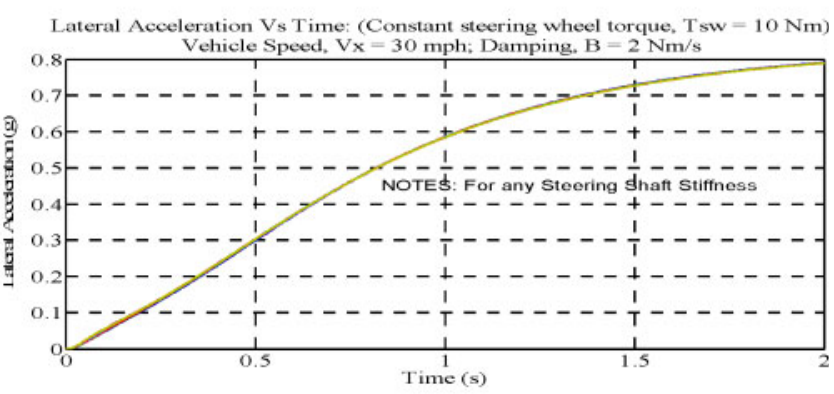

(d)

Fig. 12 Output results for a constant steering-wheel torque

ing is a function of steering-shaft design and material. Finally, the combination of the minimum acceptable steering-shaft stiffness and the minimum acceptable damping value was found to be the best choice for the properties of a steering shaft used as a back-up system for SBW during system failure. With the minimum steering-shaft stiffness, the steering ratio increases and this means that the driver needs to apply additional effort to increase the speed of rotation of the steering wheel. It was found that this is not necessarily a problem as the steering-wheel speed can adjust automatically depending on the torque applied by the driver. If the stiffness is low, the resistance to turning of the steering wheel will be small and the steering wheel speed will increase. Based on the safety aspects, the car is considered safe to be driven under this condition but the performance may be slightly under par compared with the conventional system during failure. Overall it may therefore be concluded that a car with an SBW system may be safely fitted with a low-stiffness emergency back-up system, e.g. some form of cable.

\section{REFERENCES}

1 Oh, S., Chae, H., Yun, S., and Han, C. The design of a controller for the steer-by-wire system. JSME Int. J., Ser. C, 2004, 47(3), 896-907.
2 Amberkar, S., Bolourchi, F., Demerly, J., and Millsap, S. A control system methodology for steer-by-wire systems. SAE technical paper, 200401-1106, 2004.

3 Yoshiyuki, S. Steer-by-wire system. Jap. Pat. Applic. 2006-027494, Applic. no. 2004-211019, 2006.

4 Yih, P. and Gerdes, J. C. Steer-by-wire for vehicle state estimation and control. In Proceedings of the Seventh International Symposium on Advanced vehicle control (AVEC) 04, Arnhem, The Netherlands, 23-27 August 2004, pp. 785-790 (Han University, Arnhem).

5 Cesiel, D., Gaunt, M. C., and Daugherty, B. Development of a steer-by-wire system for the GM sequel. SAE technical paper 2006-01-1173, 2006.

6 Sherwin, K. A. and DuCharme, R. T. Steer-by-wire steering apparatus with actuatable mechanism. US Pat. Applic. 2003/0141134 A1, Applic. No.10/ 059,983, 2003.

7 Itoh, K. Steering apparatus for vehicle. US Pat. Applic. 2006/0042859 A1, Applic. no. 11/206,944, 2006.

8 Mitsuhiro, M. and Yoshiteru, M. Vehicular steering gear. Jap. Pat. Applic. JP2001001907, Applic. no. JP19990176538 19990623, 2001.

9 Augustine, M. J. Mechanically linked active steering system. US Pat. 7063636, 2004, available from www.freepatentsonline.com/7063636. html.

10 Baharom, M. B., Hussain, K., and Day, A. J. Mathematical modelling of a cornering vehicle fitted with hydraulic-power assisted steering. In Proceedings of the FISITA 2006 World Automotive Congress, Yokohama, Japan, 22-27 October 2006, 
paper F2006V019, available on CD-ROM (Society of Automotive Engineers of Japan, Tokyo).

11 Pacejka, H. B. Tire and vehicle dynamics, 2002 (Butterworth-Heinemann, Oxford).

12 Post, J. W. and Law, E. H. Procedure for the characterization of friction in automobile power steering systems. SAE technical paper 960933, 1996.

13 Dorf, R. C. and Bishop, R. H. Modern control system, 10th edition, 2004 (Prentice Hall, Upper Saddle River, New Jersey).

14 Race Technology, available from www.race-technology.com.

\section{APPENDIX}

\section{Notation}

$a, b$

$a_{y}$

$B_{\mathrm{Fw}}$

$B_{1}$ distance from the centre of gravity to the front contact patch and to the rear contact patch respectively $(\mathrm{m})$ total lateral acceleration $\left(\mathrm{m} / \mathrm{s}^{2}\right)$ damping coefficient of the frontwheel assembly ( $\mathrm{N} \mathrm{ms} / \mathrm{rad}$ ) damping coefficient of the steering shaft $(\mathrm{Nm} \mathrm{s} / \mathrm{rad})$
$C_{F \alpha_{\mathrm{F}}}, C_{F \alpha_{\mathrm{R}}}$

$C_{M \alpha_{\mathrm{F}}}$

$F_{\text {Cf }}$

G

$I_{\mathrm{FW}}$

$I_{z z}$

$K_{1}$

$M_{z \mathrm{~F}}$

$r$

$\dot{r}$

$V_{x}$

$\alpha_{\mathrm{F}}$
$\beta$
$\delta_{\mathrm{F}}$
$\delta_{\mathrm{p}}$
$\delta_{\mathrm{sw}}$
$\tau_{\mathrm{f}}, F_{\mathrm{Cf}}$

front and rear cornering coefficient respectively ( $\mathrm{N} / \mathrm{rad})$

self-aligning moment coefficient ( $\mathrm{N} \mathrm{m} / \mathrm{rad})$

frictional force $(\mathrm{N})$

steering ratio

moment of inertia of the front-wheel assembly $\left(\mathrm{kg} \mathrm{m}^{2}\right)$

yaw moment of inertia $\left(\mathrm{kg} \mathrm{m}^{2}\right)$

torsion stiffness of the steering shaft ( $\mathrm{N} \mathrm{m} / \mathrm{rad}$ )

self-aligning moment $(\mathrm{Nm})$

yaw velocity ( $\mathrm{rad} / \mathrm{s}$ )

yaw acceleration $\left(\mathrm{rad} / \mathrm{s}^{2}\right)$

longitudinal speed of the vehicle $(\mathrm{m} / \mathrm{s})$

front slip angle (rad)

sideslip angle

average front-steered-wheel angle

(rad)

pinion rotation angle (rad)

steering-wheel angle (rad)

friction torque on steering wheel

( $\mathrm{N} \mathrm{m})$ 